\title{
BIBLIOMETRIA EM PERSPECTIVA: \\ DAS PESQUISAS INTERDISCIPLINARES \\ AOS RECURSOS DIGITAIS
}

\author{
Cristiana Barcelos da Silva ${ }^{1}$ \\ Universidade do Estado de Minas Gerais (UEMG) \\ Fábio Machado de Oliveira² \\ Universidade Estadual do Norte Fluminense Darcy Ribeiro (UENF-Brasil) \\ Rackel Peralva Menezes Vasconcellos ${ }^{3}$ \\ Universidade Estadual do Norte Fluminense Darcy Ribeiro (UENF-Brasil)
}

Um levantamento bibliométrico têm por característica primária, reverberar, no âmbito das instituições de pesquisa, sobre a compreensão do cenário investigativo de determinada área do conhecimento, seja para compreender o processo de construção/evolução da área, os avanços dela, suas fragilidades e/ou lacunas é uma tarefa que merece destaque na ação de investigar. Organizar, refletir, ponderar e analisar as pesquisas desenvolvidas em torno de um mote parecem verbos de ordem na pauta do trabalho investigativo.

Dito isso, o presente dossiê intitulado "Bibliometria em perspectiva: das pesquisas interdisciplinares aos recursos digitais" nos provoca a pensar em que medida elementos amplos e generalista, do campo da pesquisa, operam de maneira tão conectada a ponto de oferecer uma visão completa e substancial da realidade. Nesse sentido, inquietações, desconfortos e questionamentos que o processo analítico gere talvez sejam a condição necessária para as possibilidades de construções reflexivas, a partir de uma proposta nova de olhar: a interdisciplinar.

Partindo dessas premissas, nas investigações trazidas na presente obra, ela - a interdisciplinaridade- acaba por baralhar a própria ordem das pesquisas oferecendo uma possibilidade real de visualizações descompromissadas e desapegadas com a lógica disciplinar.

Assim, levando a cabo a natureza e princípios da envergadura do campo interdisciplinar, o dossiê em questão, propõe promover um dialogar a respeito de metodologias baseadas na Revisão Bibliométrica Sistemática (RBS) como estratégia de ampliação das possibilidades de investigações que buscam mapear categorias de análises identificadas nas produções encontradas em diversas bases de dados.

Desse modo, o que os autores desejaram foi anunciar, de maneira coletiva, sobre a necessidade de, além de compreender o panorama atual das pesquisas das suas áreas de atuação, o quanto é imprescindível tomar decisões metodológicas ao longo do processo de busca e definição de parâmetros para construção dos protocolos investigativos. Uma vez convencidos da potencial relação da RSB com o campo interdisciplinar os autores se uniram para se aventurar nessa empreitada.

\footnotetext{
${ }^{1}$ Pós-doutora em Cognição e Linguagem pela Universidade Estadual do Norte Fluminense Darcy Ribeiro (UENF-Brasil) com estágio de doutoramento no exterior na Faculdade de Ciências Sociais e Humanas (FCSH) da Universidade Nova de Lisboa (UNL-Portugal). Professora na Universidade do Estado de Minas Gerais (UEMG), MG, Brasil. ORCID: https://orcid.org/0000-0003-2196-467X. E-mail: cristianabarcelos@gmail.com

2 Pós-doutor em Cognição e Linguagem na Universidade Estadual do Norte Fluminense Darcy Ribeiro (UENF). Campos dos Goytacazes, Rio de Janeiro, Brasil. Avenida Alberto Lamego, 2000, Parque Califórnia, Campos dos Goytacazes, RJ, Brasil, CEP: 28013-602. ORCID: https://orcid.org/0000-0003-1336-2994. E-mail: fabiomac@gmail.com

${ }_{3}^{3}$ Mestra em Cognição e Linguagem na Universidade Estadual do Norte Fluminense Darcy Ribeiro (UENF). Campos dos Goytacazes, Rio de Janeiro, Brasil. Avenida Alberto Lamego, 2000, Parque Califórnia, Campos dos Goytacazes, RJ, Brasil, CEP: 28013-602. ORCID: https://orcid.org/0000-0002-8706-2380. E-mail: polianaccluna@gmail.com.
} 
i.1 | Bibliometria em perspectiva: das pesquisas interdisciplinares aos recursos digitais

Sobre a composição do dossiê, como resultado da junção das reflexões dos pesquisadores, o artigo na área da Educação Básica intitulado "Evasão Escolar e Ensino Médio: uma revisão bibliométrica" de autoria de Cristiana Barcelos da Silva apresenta uma revisão associando o problema educacional da evasão, na última etapa obrigatória de escolarização. A pesquisadora descreve o resultado das investigações indexados na base de dados Scopus Elsevier, entre os anos de 2014 e 2018, verificando que uma maior produção do conhecimento dos estudos que versam sobre a Evasão Escolar no Ensino Médio, nos últimos cinco anos, como sendo de caráter descritivo e, em menor número, as pesquisas indexadas na base de dados com propostas de ações práticas para a redução do fenômeno educacional.

Ainda na área da Educação Escolar, dessa vez no nível superior, os pesquisadores Poliana Campos Côrtes Luna, Rackel Peralva Menezes Vasconcellos, Cristiana Barcelos da Silva e Fábio Machado de Oliveira na obra "Contribuições para os estudos sobre o bem- estar na universidade à luz da Psicologia Positiva: uma análise bibliométrica" objetiva-se identificar o perfil das pesquisas científicas, capítulos de livros e livros que evidenciam o trinômio "bem-estar", "psicologia positiva", "universidade", entre os anos de 2015 a 2020. A partir de uma pesquisa descritiva, quantitativa, utilizando a base de dados Scopus como instrumento de coleta e recursos digitais os softwares VOSviewer e WordClouds como de análise. Observou-se que dos 65 documentos, somente 8 autores se interligam e os temas se conectam de forma direta. Fato que demonstra a relevância e o qual atual é a supracitada pesquisa.

Com enfoque na área da saúde a pesquisa "Contexto brasileiro das pesquisas científicas acerca da saúde ocupacional do trabalhador rural: um levantamento na base de dados Scopus Elsevier", do autor Lucas Capita, tenciona compreender as características das pesquisas brasileiras a respeito da saúde ocupacional do trabalhador rural e salienta a necessidade de incentivar ações no campo.

Abordando questões de ordem midiática, o texto trazido pelo pesquisador João Paulo Hergesel chamado de "Contribuições da revisão sistemática e bibliométrica (rsb) para os estudos de televisão: aplicabilidade do método em uma pesquisa exploratória sobre telenovela infantojuvenil" considera que são tímidos os estudos acadêmicos sobre o assunto tanto que apenas quatro foram os resultados de busca.

Ainda no campo escolar, no trabalho da linguagem e cognominado "Estudo bibliométrico sobre a prática de professores de Língua Portuguesa no Ensino Médio e o Letramento Digital" Roberta Barroso considera os atuais desafios docentes no cotidiano e bojo da produção científica.

Coadunando as áreas das Ciências Humanas, Francis Noblat e Wilson Madeira Filho, no escrito alcunhado "Buscando a interdisciplinaridade no interdisciplinar em ciências jurídicas e sociais: reflexões sobre a interdisciplinaridade a partir do programa de pós-graduação em sociologia e direito" apresenta-se um ensaio pautado na análise de teses e dissertações defendidas pelo Programa de Pós-Graduação em Sociologia e Direito da Universidade Federal Fluminense entre os anos de 2013 e 2016.

O presente dossiê reuniu portanto, investigações que buscaram descrever os passos utilizados para a elaboração da pesquisa bibliométrica. Têm de divergente, o fato de tomarem como foco diferentes motes de análise. Como ponto convergente, procuram partir do reconhecimento da temática e compreender a diversidade de interpretações inerentes a elas. Em todas, aventurou-se por uma averiguação das investigações em uma base de dados e descreveu-se de modo detalhado as etapas percorridas na fase de planejamento da revisão, identificação do tipo e escolha da base de dados mais apropriada a ser explorada, além da definição das estratégias de busca. Por fim, apresentaram o número de trabalhos extraídos e algumas descobertas referentes a apreciação e análise da revisão sistemática bibliométrica.

Assim, a intenção do dossiê, foi debater a respeito de normas, regras, parâmetros de configuração e estratégias de busca, escolha da base de dados, planejamento para a organização 
[i.j] Cristiana Barcelos Da Silva, Fábio Machado de Oliveira, Rackel Peralva Menezes Vasconcellos documental dos achados, seleção dos artigos encontrados nos periódicos e disposição dos portfólios bibliográficos necessários para a construção de uma pesquisa científica de caráter interdisciplinar.

Editores convidados. 